\title{
Pengaruh Komunikasi Pemasaran melalui Event dan Iklan terhadap Citra Merek Shopee
}

\author{
Jacqueline, Suherman Kusniadji \\ jacquelinemuliono.jm@gmail.com, kusniadjiherman@gmail.com \\ Fakultas Ilmu Komunikasi Universitas Tarumanagara
}

\begin{abstract}
This study aims to determine the effect of Marketing Communication through Events and Ads on Shopee Brand Images. The theory used in this study is marketing communication, event, advertising, e-commerce, and brand image. This study uses quantitative research methods with survey methods. The research technique used is non probability with a purposive sampling approach with 100 people as respondents. Data collection techniques using questionnaires and literature studies. Test requirements analysis using tests of validity, reliability and normality. Data analysis using multiple correlation coefficients, coefficient of determination, multiple linear regression analysis, $T$ test and $F$ test. The results of the multiple correlation coefficient test are 0.861 which means having a relationship between variables is very strong, while the coefficient of determination is $74.1 \%$ brand image. Shopee is influenced by events and advertisements. The results of the T-test of the two variables are known that Ha is accepted, meaning that event and advertising activities partially influence the Shopee brand image. Based on the F test results it is known that F table (3.09) < F count (138.406) then Ha is accepted, meaning that the event variables and advertisements have an effect on the Shopee brand image.
\end{abstract}

Keywords: Marketing Communication, Event, Advertising, E-Commerce, Brand Image

\begin{abstract}
Abstrak
Penelitian ini bertujuan untuk mengetahui pengaruh Komunikasi Pemasaran melalui Event dan Iklan terhadap Citra Merek Shopee. Teori yang digunakan dalam penelitian ini adalah komunikasi pemasaran, event, iklan, e-commerce, dan citra merek. Penelitian ini menggunakan metode penelitian kuantitatif dengan metode survey. Teknik penelitian yang digunakan adalah non probability dengan pendekatan purposive sampling, responden sebanyak 100 orang. Teknik pengumpulan data dengan menggunakan kuesioner dan studi kepustakaan. Uji persyaratan analisis menggunakan uji validitas, reliabilitas, dan normalitas. Analisis data menggunakan koefisien korelasi berganda, koefisien determinasi, analisis regresi linier berganda, uji $\mathrm{T}$ dan uji $\mathrm{F}$. Hasil dari uji koefisien korelasi berganda sebesar 0,861 artinya memiliki hubungan antar variabel sangat kuat, sedangkan pada koefisien determinasi didapatkan hasil sebesar $74,1 \%$ citra merek Shopee dipengaruhi oleh event dan iklan. Hasil uji T kedua variabel diketahui bahwa Ha diterima, artinya kegiatan kegiatan event dan iklan secara parsial berpengaruh terhadap citra merek Shopee. Berdasarkan hasil uji $\mathrm{F}$ diketahui $\mathrm{F}$ tabel $(3,09)<\mathrm{F}$ hitung $(138,406)$ maka Ha diterima, artinya variabel event dan iklan secara bersama-sama berpengaruh terhadap citra merek Shopee.
\end{abstract}

Kata Kunci: Komunikasi Pemasaran, Event, Iklan, E-Commerce, Citra Merek 


\section{Pendahuluan}

Era globalisasi saat ini menjadikan persaingan dalam dunia usaha semakin kompetitif sehingga mengakibatkan setiap perusahaan berusaha untuk menjadi pemenang dalam memasarkan produk dan jasanya. Di era globalisasi saat ini, penggunaan teknologi merupakan suatu hal yang sangat penting sebagai penunjang segala bentuk kegiatan. Gaya hidup masyarakat juga semakin berkembang seiring dengan perkembangan jaman dan teknologi.

Konsumen saat ini sudah mulai cerdas dan semakin selektif dalam memilih produk dan jasa yang mereka gunakan, hal ini menuntut perusahaan semakin sensitif terhadap persaingan dalam dunia bisnis dengan menciptakan cara-cara baru agar dapat menjaga perusahaan untuk dapat hidup dan berkembang. Perusahaan harus bisa menentukan strategi kegiatan pemasaran yang tepat agar usahanya dapat bertahan dan tujuan utama dari perusahaan tersebut dapat tercapai.

Perkembangan teknologi informasi yang terus berkembang dengan pesat telah membawa era baru bagi manusia untuk memasuki dunia yang serba cepat. Salah satunya seperti internet yang dapat membantu penggunanya dengan mudah, cepat, dan praktis dalam melakukan berbagai aktivitas kehidupan sehari-hari, misalnya membaca berita secara online, berbelanja kebutuhan sehari-hari, dan sebagainya. Dengan adanya perkembangan teknologi, kini teknologi pun diciptakan untuk menjadi sarana untuk memudahkan dan mendukung aktivitas bisnis, seperti membuat atau menyediakan toko online sebagai bagian dari e-commerce tanpa harus melakukan pembelian secara langsung atau tatap muka antara penjual dan pembeli.

E-commerce seperti Shopee merupakan salah satu dari sepuluh perusahaan $e$ commerce terbesar di Indonesia dan merupakan e-commerce dengan urutan ke lima dengan perkiraan lalu lintas pengguna sebanyak 39.100.000 selama per bulan (https://aseanup.com/top-e-commerce-sites-indonesia/). Shopee merupakan jenis $e$ commerce $\mathrm{C} 2 \mathrm{C}$ (Customer to Customer), yang merupakan transaksi jual beli antar konsumen. Shopee memberikan fasilitas gratis ongkos kirim untuk ke seluruh Indonesia, menyediakan fitur "koin Shopee" yang dapat digunakan konsumen untuk mendapatkan potongan pembelian, serta membekali pembeli mendapatkan transaksi yang aman dengan sistem "Garansi Shopee" yaitu jaminan uang akan kembali 100\% jika barang tidak sampai.

Shopee adalah e-commerce yang menawarkan berbagai macam kategori produk, mulai dari produk kecantikan, fashion, elektronik, otomotif sampai dengan produk untuk kebutuhan sehari-hari. Shopee hadir dalam bentuk aplikasi mobile untuk memudahkan para penggunanya dalam melakukan kegiatan belanja online tanpa harus membuka website melalui perangkat komputer. Sejak peluncurannya Shopee mengalami perkembangan yang sangat pesat, hingga saat ini aplikasi Shopee sudah didownload lebih dari 10 juta pengguna dan menjadi top 1 free kategori shopping di play store.

Setiap perusahaan e-commerce melakukan berbagai macam kegiatan komunikasi pemasaran untuk menarik perhatian konsumen agar mengingat dan menggunakan produk atau jasa yang ditawarkan, hal ini sejalan dengan (Kotler dan Keller, 2009:172) bahwa komunikasi pemasaran adalah sarana perusahaan untuk membujuk, mengingatkan dan menginformasikan konsumen baik secara langsung maupun tidak langsung tentang produk dan merek yang dijual. 
Kotler dan Keller (2009), terdapat delapan model komunikasi utama dalam bauran komunikasi pemasaran yang menunjang komunikasi pemasaran, yaitu iklan, promosi penjualan, acara dan pengalaman, hubungan masyarakat, pemasaran langsung, pemasaran interaktif, dan penjualan personal. Kegiatan komunikasi pemasaran yang dilakukan oleh Shopee antara lain periklanan, promosi penjualan, acara (event), pemasaraan langsung, dan pemasaran interaktif. Kegiatan komunikasi pemasaran yang dilakukan oleh Shopee adalah untuk memperkenalkan perusahaan agar tercipta komunikasi yang positif di tingkat konsumen sehingga citra perusahaan dapat lebih baik di mata konsumen.

Komunikasi pemasaran dapat digunakan untuk menggambarkan merek yang ditawarkan perusahaan serta membantu perusahaan untuk membangun merek di benak konsumen. Hal ini sejalan dengan yang dikemukakan oleh Kotler dan Keller (2008:204) bahwa komunikasi pemasaran dapat berkontribusi dalam menciptakan citra merek dengan membangun merek dalam benak konsumen.

Berdasarkan uraian latar belakang diatas, peneliti menyadari bahwa kegiatan komunikasi pemasaran dapat mempengaruhi citra merek pada Shopee. Dalam hal ini, peneliti memilih kegiatan komunikasi pemasaran melalui event dan iklan karena kedua kegiatan tersebut yang paling menonjol dan gencar dilakukan oleh Shopee, kemudian ada juga kegiatan komunikasi pemasaran yang tidak dilakukan oleh Shopee, seperti penjualan personal karena Shopee merupakan perusahaan yang menyediakan jasa. Sedangkan peneliti memilih e-commerce Shopee sebagai objek penelitian karena Shopee merupakan e-commerce yang masih tergolong baru beroperasi di Indonesia namun mampu menjadi top 10 e-commerce di Indonesia, selain itu juga Shopee merupakan e-commerce yang mendapat beberapa penghargaan dalam bidang marketing dan periklanan yang sesuai dengan penelitian peneliti.

Penelitian ini bertujuan untuk mengetahui ada atau tidaknya pengaruh kegiatan komunikasi pemasaran melalui event terhadap citra merek Shopee, untuk mengetahui ada atau tidaknya pengaruh kegiatan komunikasi pemasaran melalui iklan terhadap citra merek Shopee, dan untuk mengetahui ada atau tidaknya pengaruh kegiatan komunikasi pemasaran melalui event dan iklan terhadap citra merek Shopee.

\section{Metode Penelitian}

Pendekatan penelitian yang digunakan pada penelitian ini adalah pendekatan penelitian kuantitatif. Metode penelitian kuantitatif merupakan metode penelitian yang berlandasakan pada filsafat positivisme, metode kuantitatif digunakan untuk meneliti pada populasi atau sampel tertentu serta analisis data bersifat kuantitatif/statistik dengan tujuan untuk menguji hipotesis yang telah ditetapkan (Sugiyono, 2017). Dalam penelitian ini, peneliti memilih pendekatan penelitian kuantitatif dengan metode survey. Menurut Sugiyono (2017:6), metode survey merupakan suatu metode untuk mendapatkan data dari tempat tertentu, peneliti melakukan pengumpulan data, misalnya dengan mengedarkan kuesioner, wawancara dan lainnya.

Berdasarkan data yang diakses melalui website resmi Shopee, Shopee telah di download sebanyak kurang lebih 43 juta pengguna, sedangkan data yang diakses melalui channel Youtube Shopee Indonesia, iklan Shopee telah ditonton sebanyak kurang lebih 80 juta viewers. Dalam penelitian ini, peneliti menetapkan jumlah sampel sebanyak 100 responden, dengan kriteria sampel yang telah ditentukan dan sesuai dengan penelitian peneliti. 
Teknik penentuan sampel yang digunakan pada penelitian ini didasarkan pada metode non probability sampling dengan menggunakan pendekatan purposive sampling. Data dikumpulkan dengan penyebaran kuesioner dengan menggunakan skala likert. Data primer dalam penelitian ini diperoleh melalui penyebaran kuesioner. Sedangkan data sekunder didapat melalui studi kepustakaan dan internet. Untuk mengetahui keabsahan data dalam penelitian ini, peneliti menggunakan uji validitas, uji reliabilitas, dan uji normalitas. Sedangkan untuk pengolahan data dalam penelitian ini, peneliti menggunakan uji koefisien korelasi berganda, uji koefisien determinasi, analisis regresi linier berganda, uji $\mathrm{T}$, dan uji F. Hipotesis dalam penelitian ini adalah sebagai berikut:

$\mathrm{Ha}_{1}$ : terdapat pengaruh event terhadap citra merek Shopee.

$\mathrm{Ho}_{1}$ : tidak terdapat pengaruh event terhadap citra merek Shopee.

$\mathrm{Ha}_{2}$ : terdapat pengaruh iklan terhadap citra merek Shopee.

$\mathrm{Ho}_{2}$ : tidak terdapat pengaruh iklan terhadap citra merek Shopee.

$\mathrm{Ha}_{3}$ : terdapat pengaruh event dan iklan terhadap citra merek Shopee.

$\mathrm{Ho}_{3}$ : tidak terdapat pengaruh event dan iklan terhadap citra merek Shopee.

\section{Hasil Temuan dan Diskusi}

Berdasarkan nilai rata-rata untuk variabel $\mathrm{X}_{1}$ (event), dimensi tertinggi ada pada dimensi enterprise yang paling mempengaruhi citra merek Shopee. Untuk nilai rata-rata variabel $\mathrm{X}_{2}$ (iklan), dimensi tertinggi ada pada dimensi meaningful yang paling berpengaruh terhadap citra merek Shopee. Pada variabel $\mathrm{X}_{2}$ (iklan), selain dimensi meaningful, nilai rata-rata pada dimensi distincitive juga memiliki nilai yang tinggi dalam mempengaruhi citra merek Shopee.

Peneliti menyebarkan kuesioner kepada 100 responden. Dari 100 responden, mayoritas responden adalah perempuan. Dari segi usia, mayoritas responden berusia 17-25 tahun. Dengan mayoritas domisili Jakarta Barat dan mayoritas berstatus mahasiswa/pelajar.

Dari data 100 responden, peneliti melakukan keabsahan data melalui uji validitas, uji reliabilitas, dan uji normalitas untuk menguji 22 pernyataan yang terdapat pada kuesioner.

\begin{tabular}{|c|c|c|c|c|}
\hline \multicolumn{2}{|c|}{ No. Soal } & R Hitung & R Tabel & Keterangan \\
\hline \multirow{8}{*}{$\mathrm{X}_{1}$} & P1 & 0,755 & 0,2 & Valid \\
\hline & $\mathrm{P} 2$ & 0,749 & 0,2 & Valid \\
\hline & P3 & 0,790 & 0,2 & Valid \\
\hline & P4 & 0,825 & 0,2 & Valid \\
\hline & P5 & 0,852 & 0,2 & Valid \\
\hline & P6 & 0,815 & 0,2 & Valid \\
\hline & P7 & 0,749 & 0,2 & Valid \\
\hline & P8 & 0,718 & 0,2 & Valid \\
\hline \multirow{7}{*}{$\mathrm{X}_{2}$} & P9 & 0,708 & 0,2 & Valid \\
\hline & $\mathrm{P} 10$ & 0,720 & 0,2 & Valid \\
\hline & P11 & 0,750 & 0.2 & Valid \\
\hline & $\mathrm{P} 12$ & 0,760 & 0,2 & Valid \\
\hline & $\mathrm{P} 13$ & 0,751 & 0,2 & Valid \\
\hline & P14 & 0,758 & 0,2 & Valid \\
\hline & P15 & 0,793 & 0,2 & Valid \\
\hline
\end{tabular}


Jacqueline, Suherman Kusniadji: Pengaruh Komunikasi Pemasaran melalui Event dan Iklan terhadap Citra Merek Shopee

\begin{tabular}{ccccc} 
& P16 & 0,790 & 0,2 & Valid \\
& P17 & 0,816 & 0,2 & Valid \\
Y & P18 & 0,766 & 0,2 & Valid \\
& P19 & 0,874 & 0,2 & Valid \\
& P20 & 0,738 & 0,2 & Valid \\
& P21 & 0,789 & 0,2 & Valid \\
& P22 & 0,683 & 0,2 & Valid \\
\hline
\end{tabular}

Uji Reliabilitas $\mathrm{X}_{1}$

Setelah diuji menggunakan SPSS, peneliti mendapatkan hasil 0,786 untuk pernyataan variabel $\mathrm{X}_{1}$ (Event). Pernyataan untuk variabel $\mathrm{X}_{1}$ (Event) dinyatakan reliabel, karena nilai Cronbach's Alpha >0,6 yaitu 0,786 >0,6.

Uji Reliabilitas $\mathrm{X}_{2}$

Setelah diuji menggunakan SPSS, peneliti mendapatkan hasil 0,784 untuk pernyataan $\mathrm{X}_{2}$ (Iklan). Pernyataan untuk variabel $\mathrm{X}_{2}$ (Iklan) dinyatakan reliabel, karena nilai Cronbach's Alpha > 0,6 yaitu 0,784 >0,6.

Uji Reliabilitas Y

Setelah diuji menggunakan SPSS, peneliti mendapatkan hasil 0,789 untuk pernyataan Y (Citra Merek). Pernyataan untuk variabel Y (Citra Merek) dinyatakan reliabel, karena nilai Cronbach's Alpha >0,6 yaitu 0,789>0,6.

Uji Normalitas

Setelah diuji menggunakan SPSS, hasil uji normalitas menunjukkan nilai signifikansi sebesar 0,637, karena hasil signifikansi lebih besar dari 0,05 maka data dalam penelitian ini dinyatakan terdistribusi normal.

Hasil Analisis Data:

Uji Koefisien Korelasi Berganda

Gambar 1. Koefisien Korelasi Berganda

Model Summary
\begin{tabular}{|l|l|r|r|r|}
\hline Model & $\mathrm{R}$ & R Square & $\begin{array}{c}\text { Adjusted R } \\
\text { Square }\end{array}$ & $\begin{array}{c}\text { Std. Error of } \\
\text { the Estimate }\end{array}$ \\
\hline 1 & $.861^{\mathrm{a}}$ & .741 & .735 & 2.30887 \\
\hline
\end{tabular}
a. Predictors: (Constant), Iklan $(\alpha 2)$, Event $(\alpha 1)$
b. Dependent Variable: Citra Merek $(())$

Sumber: SPSS (2018)

Setelah diuji menggunakan SPSS, peneliti mendapatkan hasil bahwa koefisien korelasi (R) dari variabel $\mathrm{X}_{1}, \mathrm{X}_{2}$ dan $\mathrm{Y}$ dalam penelitian ini sebesar 0,861. Apabila nilai $\mathrm{R}$ sebesar 0,861 menunjukkan hubungan antara event $\left(\mathrm{X}_{1}\right)$, iklan $\left(\mathrm{X}_{2}\right)$ dan citra merek (Y) adalah sangat kuat, pernyataan ini didasari oleh Sugiyono (2017:231).

Koefisien Determinasi

Setelah diuji menggunakan SPSS, peneliti mendapatkan hasil nilai koefisien determinasi dengan melihat angka yang ada pada $\mathrm{R}$ Square. Hasil dari R Square adalah 0,741 sama dengan $74,1 \%$ yang artinya kemampuan event dan iklan dalam mempengaruhi citra merek Shopee cukup kuat karena nilai koefisien determinasi mendekati angka satu dan dapat dikatakan bahwa sebesar 74,1\% citra merek Shopee dipengaruhi oleh event dan iklan, sedangkan sisanya 25,9\% menunjukkan citra merek Shopee dipengaruhi oleh faktor-faktor lain.

Analisis Regresi Linier Berganda 
Gambar 2. Analisis Regresi Linier Berganda dan Uji T

\begin{tabular}{|c|c|c|c|c|c|c|c|c|}
\hline \multicolumn{9}{|c|}{ Coefficients $^{a}$} \\
\hline \multirow[b]{2}{*}{ Model } & & \multicolumn{2}{|c|}{ Unstandardized Coefficients } & \multirow{2}{*}{$\begin{array}{c}\begin{array}{c}\text { Standardized } \\
\text { Coefficients }\end{array} \\
\text { Beta }\end{array}$} & \multirow[b]{2}{*}{$t$} & \multirow[b]{2}{*}{ Sig. } & \multicolumn{2}{|c|}{ Collinearity Statistics } \\
\hline & & $B$ & Std. Error & & & & Tolerance & VIF \\
\hline \multirow[t]{3}{*}{1} & (Constant) & 1.603 & 1.525 & & 1.051 & .296 & & \\
\hline & Event $(X 11)_{1}$ & .362 & .066 & 405 & 5.514 & .000 & 496 & 2.016 \\
\hline & Iklan $(\alpha 2)$ & .526 & .074 & .524 & 7.142 & .000 & .496 & 2.016 \\
\hline
\end{tabular}

Sumber: SPSS (2018)

$$
\mathbf{Y}=\boldsymbol{\alpha}+\mathbf{b}_{1} \mathbf{X}_{1}+\mathbf{b}_{2} \mathbf{X}_{2}
$$

Setelah diuji menggunakan SPSS, peneliti mendapatkan hasil nilai sebesar 1,603 menyatakan konstanta dari fungsi regresi yang menunjukkan bahwa jika tidak ada kenaikan variabel $\mathrm{X}_{1}$ (event) dan $\mathrm{X}_{2}$ (iklan), maka variabel Y (citra merek) akan mencapai 1,603. Setiap ada penambahan 1 angka atau perubahan variabel $\mathrm{X}_{1}$ (event), maka variabel Y (citra merek) akan mengalami peningkatan sebesar 0,362 dan setiap ada penambahan 1 angka atau perubahan variabel $\mathrm{X}_{2}$ (iklan), maka variabel Y (citra merek) akan mengalami peningkatan sebesar 0,526. Hal ini menunjukkan semakin besar nilai variabel X maka akan semakin mempengaruhi kenaikan nilai Y.

Uji T

Setelah diuji menggunakan SPSS, peneliti mendapatkan nilai $t_{\text {tabel }}$ adalah 1,988. Hasil uji $\mathrm{T}$ terhadap $\mathrm{X}_{1}$ adalah nilai $t_{\text {hitung }}$ variabel $\mathrm{X}_{1}$ adalah 5,514, maka $t_{\text {hitung }} \geq t_{\text {tabel }}$ yaitu $5,514 \geq 1,988$ serta nilai sig $<\alpha$ yaitu $0,000<0,05$, maka Ha diterima, artinya terdapat pengaruh event berpengaruh terhadap citra merek Shopee. Untuk hasil uji $\mathrm{T}$ terhadap $\mathrm{X}_{2}$ adalah nilai $t_{\text {hitung }}$ variabel $\mathrm{X}_{2}$ adalah 7,142 , maka $t_{\text {hitung }} \geq t_{\text {tabel }}$ yaitu $7,142 \geq 1,988$, serta nilai sig $<\alpha$ yaitu $0,000<0,05$, maka Ha diterima, artinya terdapat pengaruh iklan terhadap citra merek Shopee.

Uji F

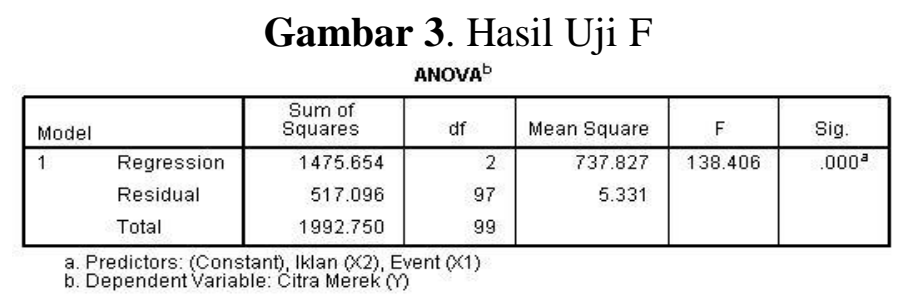

Sumber: SPSS (2018)

Setelah diuji menggunakan SPSS, peneliti mendapatkan nilai $F_{\text {tabel }}$ adalah 3,09 dan nilai $F_{\text {hitung }}$ adalah 138,406 maka $F_{\text {tabel }}<F_{\text {hitung }}$ yaitu 138,406 <3,09, serta nilai sig $<0,05$ yaitu $0,000<0,05$. Hal ini dapat dikatakan hasil uji F adalah Ho ditolak dan Ha diterima, artinya variabel $\mathrm{X}_{1}$ dan variabel $\mathrm{X}_{2}$ secara bersama-sama mempengaruhi variabel $\mathrm{Y}$, maka terdapat pengaruh event dan iklan terhadap citra merek Shopee. 
Jacqueline, Suherman Kusniadji: Pengaruh Komunikasi Pemasaran melalui Event dan Iklan terhadap Citra Merek Shopee

\section{Simpulan}

Event termasuk salah satu kegiatan komunikasi pemasaran yang sangat bermanfaat dalam membangun awareness suatu merek dan meningkatkan citra merek suatu perusahaan, karena kegiatan event bersentuhan langsung dengan target pasar menurut Sulaksana (2007:40-41). Tidak hanya kegiatan event, namun iklan juga dapat membangun dan membentuk citra merek suatu perusahaan, Menurut Moriarty, Mitchell, \& Wells (2009:62) beberapa keunggulan dari iklan adalah dapat menjangkau audiens secara luas, sarana untuk memperkenalkan produk dan merek kepada masyarakat, salah satu sarana untuk membangun awareness, sarana untuk meningkatkan citra merek, menyediakan informasi, mengingatkan konsumen, serta mempersuasi konsumen untuk tertarik terhadap suatu produk atau merek.

Dalam variabel event $\left(\mathrm{X}_{1}\right)$ terdapat 3 dimensi, yaitu entertainment, excitement, dan enterprise (Leonard H. Hoyle, 2006:1-2). Dimensi entertaiment dapat mempengaruhi citra merek karena suatu event yang dilaksanakan Shopee telah memberikan manfaat yang baik dengan memberikan hiburan terhadap peserta yang berkunjung dan membuat pengunjung merasakan langsung terhadap event yang diadakan. Selain itu pada dimensi excitement, peserta merasakan kepuasan, kebahagiaan, dan kesenangan dari acara yang diadakan oleh Shopee.

Dimensi enterprise merupakan dimensi tertinggi dalam mempengaruhi citra merek, hal ini tentu karena konsep event yang telah dibuat Shopee telah dilakukan dengan baik. Dalam meningkatkan citra merek melalui kegiatan event, konsep event yang baik, menarik dan kreatif merupakan hal yang perlu diperhatikan perusahaan. Perusahaan butuh membuat sebuah kegiatan atau acara yang inovatif, kreatif, dan menarik agar dapat mengajak peserta secara langsung, sehingga dapat mengetahui dan merasakan event yang diadakan.

Dalam variabel iklan $\left(\mathrm{X}_{2}\right)$ terdapat tiga dimensi yaitu meaningful, believable, dan distinctive (Kotler dan Armstrong 2012:466). Dimensi meaningful merupakan dimensi tertinggi dalam mempengaruhi citra merek Shopee, artinya dalam meningkatkan citra merek Shopee, iklan yang dilakukan harus bermakna, sehingga dapat menunjukkan manfaat dan membuat konsumen tertarik dan menginginkan suatu produk.

Dimensi believable juga mempengaruhi citra merek Shopee, karena iklan yang dibuat Shopee dapat dipercaya oleh masyarakat. Iklan yang disampaikan dan dibuat oleh Shopee memberikan informasi yang benar dan manfaat seperti yang dijanjikan. Selain itu, dimensi distinctive juga memiliki nilai yang tidak jauh berbeda dengan dimensi meaningful, karena selain iklan yang dilakukan bermakna, iklan yang dilakukan Shopee juga memiliki ciri khas dan berbeda, sehingga produk atau jasa yang diiklankan lebih baik dan berbeda dengan kompetitor lainnya. Iklan yang unik dan berbeda yang dilakukan Shopee dapat membentuk citra merek dari Shopee tersendiri di dalam benak masyarakat.

Kesimpulan hasil dari penelitian ini adalah hubungan antara variabel event $\left(\mathrm{X}_{1}\right)$ dan variabel $\left(\mathrm{X}_{2}\right)$ terhadap variabel citra merek $(\mathrm{Y})$ adalah sangat kuat, karena nilai dari koefisien korelasi dalam penelitian ini sebesar 0,861. Hasil koefisien determinasi, dikatakan bahwa citra merek Shopee dipengaruhi sebesar $74,1 \%$ oleh event dan iklan, sementara sisanya $25,9 \%$ dipengaruhi oleh variabel-variabel lain. Kegiatan Komunikasi Pemasaran melalui event dan iklan mempengaruhi citra merek Shopee baik secara parsial maupun bersama-sama. 


\section{Ucapan Terima Kasih}

Penulis mengucapkan terima kasih kepada Bapak Drs. Suherman Kusniadji, M.M., M.I.Kom., sebagai Dosen Pembimbing yang telah meluangkan waktunya untuk membimbing penulis serta kedua orang tua, responden dan sahabat penulis yang telah memberikan dukungan kepada penulis.

\section{Daftar Pustaka}

Hoyle, Leonard H. (2006). Event Marketing. Jakarta: Penerbit PPM.

Kotler, Philip dan Gary Armstrong. (2012). Prinsip-Prinsip Pemasaran. Edisi 13. Jilid 1. Jakarta: Erlangga.

Kotler, Philip dan Kevin Lane Keller. (2009). Alih Bahasa: Benyamin Molan. Manajemen Pemasaran. Edisi Keduabelas. Jilid 1. Cetakan Keempat. Jakarta: PT. Indeks.

Kotler, Philip dan Kevin Lane Keller. (2008). Manajemen Pemasaran. Edisi Ketigabelas. Jilid 2. Jakarta: Erlangga.

Moriarty, Mitchell, Wells. (2009). Advertising Principle and Practice, Eight Edition. New Jersey: Pearson Prentice Hall.

Sugiyono. (2017). Metode Penelitian Kuantitatif, Kualitatif, dan R\&D. Bandung: Alfabeta.

Sulaksana, Uyung. (2007). Integrated Marketing Communication. Yogyakarta: Pustaka Pelajar.

https://aseanup.com/top-e-commerce-sites-indonesia/ 